\title{
Solvent Extraction of Lanthanum Ion from Chloride Medium by Di-(2-ethylhexyl) Phosphoric Acid with a Complexing Method
}

\author{
Shaohua Yin, Wenyuan Wu*, Xue Bian, Yao Luo, Fengyun Zhang \\ School of Materials and Metallurgy, Northeastern University, Shenyang, China \\ Email: *wuwy@smm.neu.edu.cn
}

Received December 26, 2012; revised January 30, 2013; accepted February 10, 2013

Copyright (C) 2013 Shaohua Yin et al. This is an open access article distributed under the Creative Commons Attribution License, which permits unrestricted use, distribution, and reproduction in any medium, provided the original work is properly cited.

\begin{abstract}
Solvent extraction experiments of $\mathrm{La}(\mathrm{III})$ with di-(2-ethylhexyl)phosphoric acid (P204) from chloride solution in the presence of a complexing agent (lactic acid) have been performed. The effective separation factors can be achieved when the complexing agent is added to the aqueous phase of the extraction system. The complexing agent lactic acid can be effectively recycled using tributyl phosphate (TBP) as extractant, by the use of a countercurrent extraction process, and the chemical oxygen demand (COD) value in the raffinate is $57.7 \mathrm{mg} / \mathrm{L}$, which meets the emission standards of pollutants from rare earths industry. Thus, the simple and environment-friendly complexing method has been proved to be an effective strategy for separating light rare earths, and provides a positive influence on the purification of $\mathrm{La}(\mathrm{III})$.
\end{abstract}

Keywords: La(III); Extraction and Separation; P204 Extractant; Lactic Acid; TBP

\section{Introduction}

Rare earths are important elements, from an industrial point of view. They are extensively used in the metallurgy, lasers, magnets, and batteries. Lanthanum (La), for example, one of the most abundant rare earths, is of current commercial interest as it is used in the hydrogen storage materials, various alloy materials, etc. With the increasing demand for it, the separation and purification of $\mathrm{La}$ (III) have gained considerable importance.

Actually, solvent extraction is a classical chemical analytical method, playing an important role as a separation technique [1]. Saponified acidic extractant such as di-2-ethylhexyl phosphoric acid (P204) has been used to separate $\mathrm{La}(\mathrm{III})$ and rare earths under some conditions, which can enhance the extraction capacity of acidic extractants, but the resulting loss of ammonium ion to aqueous phase causes serious pollution [2,3], which becomes an important issue in the current rare-earth industry. Therefore, it is essential to find a new path for separating $\mathrm{La}(\mathrm{III})$ from the adjacent REs.

Up to date, much effort has been devoted to exploring some new extraction systems or extractants superior to the existing saponified extraction system, such as synergistic extraction systems [4-6], ionic liquids (ILs) [7-9]

\footnotetext{
${ }^{*}$ Corresponding author.
}

containing functional groups used in the rare-earth ions extraction and separation. One of the most effective methods for improving the separation is to add a water-soluble complexing agent into the aqueous phase [10]. Sujatha studied the separation of $\mathrm{Ce}(\mathrm{III})$ and $\mathrm{Nd}(\mathrm{III})$ using the glycine as complexing agent, and found the average separation factor between these lanthanides was improved from 3.2 to 3.8 [11]. Similar trends have been found in the separation of the lanthanides using other complexing agents such as EDTA, DTPA and HEDTA [12-16]. However, the complexing agents have high cost and are difficult to be recycled.

We investigated the extraction of $\mathrm{La}(\mathrm{III})$ using a complexing agent citric acid with unsaponified P204, and found the extraction effect was as good as the saponified system [17]. However, some disadvantages still exist in these processes, such as very high extraction acidity and a difficult stripping. Hence, there is a growing interest in the development of new systems using a complexing agent hydroxy carboxylic acid for effective separation of REs. As a kind of hydroxy carboxylic acid, lactic acid (abbreviated as HLac) is similar to the citric acid, and is currently a promising option for the hydrometallurgical separation of the trivalent lanthanides. The separation of $\operatorname{Pr}(\mathrm{III}) / \mathrm{Ce}(\mathrm{III})$ using the HLac has been investigated, and the extraction performance is better than that without the complexing agent [18]. 
In this paper, the extraction of $\mathrm{La}(\mathrm{III})$ using the unsaponified P204 in the presence of the HLac in the laboratory was investigated. The various extraction effects on different $\mathrm{La}(\mathrm{III})$ were reported and considered for the separation of $\mathrm{La}$ (III) from the adjacent rare earths.

\section{Materials and Methods}

\subsection{Materials}

P204 and TBP supplied by Tianjin Kermel Chemical Reagent Co. Ltd. were used without purification and diluted in sulphonating kerosene. $\mathrm{A} \mathrm{LaCl}_{3}$ solution with a concentration of $0.2 \mathrm{~mol} / \mathrm{L}$ was prepared by dissolving lanthanum carbonate with a certain proportion of HLac and a small amount of $\mathrm{HCl}$. Lactic acid was supplied by Sinopharm Chemical Reagent Co. Ltd. All other chemicals used were of analytical reagent grade.

Digital pH meter (pHs-3C, Shanghai Rex Instruments Factory), calibrated daily with 4.01 and 6.86 standard buffer solutions, was employed to measure $\mathrm{pH}$ values of the aqueous phase. An Agilent 1100 model HPLC was employed to measure the concentration of lactic acid in the recycling experiments.

\subsection{Solvent Extraction Procedure}

For the equilibrium experiments, equal volumes $(20 \mathrm{~mL})$ of the aqueous and P204 extractant were mixed and shaken for $30 \mathrm{~min}$ at $298 \pm 1 \mathrm{~K}$ using a mechanical shaker. After phase separation, the concentration of $\mathrm{La}^{3+}$ left in the aqueous phase was analyzed by titration with a standard solution of EDTA at pH 5.5 using xylenol orange as an indicator, and that in the organic phase was obtained by mass balance. Distribution ratio was obtained by $D=\left[\mathrm{La}^{3+}\right]_{o} /\left[\mathrm{La}^{3+}\right]_{a}$, where " $a$ " and " $o$ " denote aqueous phase and organic phase. $\mathrm{pH}$ value was determined after extraction and phase separation.

For the recycling experiments, equal volumes $(10 \mathrm{~mL})$ of the raffinate after the above extraction and TBP extractant were mixed and shaken for $30 \mathrm{~min}$ at $298 \pm 1 \mathrm{~K}$ using a mechanical shaker. The HLac concentration was analyzed by a HPLC method after entire stripping, and the extraction efficiency $E$ is defined as follows:

$$
E \%=\frac{[\mathrm{HLac}]_{t}-[\mathrm{HLac}]_{a}}{[\mathrm{HLac}]_{t}}
$$

where $[\mathrm{HLac}]_{t}$ and $[\mathrm{HLac}]_{a}$ represent initial and strip liquor concentrations of HLac in aqueous phase, respectively.

\section{Results and Discussion}

\subsection{The Effect of Acidity on Extraction of La(III)}

It should be noted that the $\mathrm{pH}$ value in the aqueous solu- tion plays an important role in the extraction system with acidic extractants. The plots of distribution ratio $(D)$ versus aqueous $\mathrm{pH}$ are shown in Figure 1. It can be seen that the $D$ shows an increasing trend with $\mathrm{pH}$ increasing at a constant concentration of lactic acid.

\subsection{The Effect of HLac Concentration on the Extraction}

The effect of HLac concentration on the extraction of $\mathrm{La}^{3+}$ with P204 is studied and the results are shown in Figure 2. From Figure 2, it can be found that the distribution ratios of $\mathrm{La}$ (III) increase with the increasing of lactic acid concentration, and $D$ reaches largest at the 0.6 $\mathrm{mol} / \mathrm{L}$ HLac concentration and initial aqueous $\mathrm{pH} 3.5$. This may be explained in terms of the buffering action of HLac, which slows down the effect of higher acidity in the raffinate on the distribution ratios.

In practical application, the effect of initial aqueous $\mathrm{pH}$ is considered to be an important parameter, primarily because the acidity control of the aqueous phase is one of

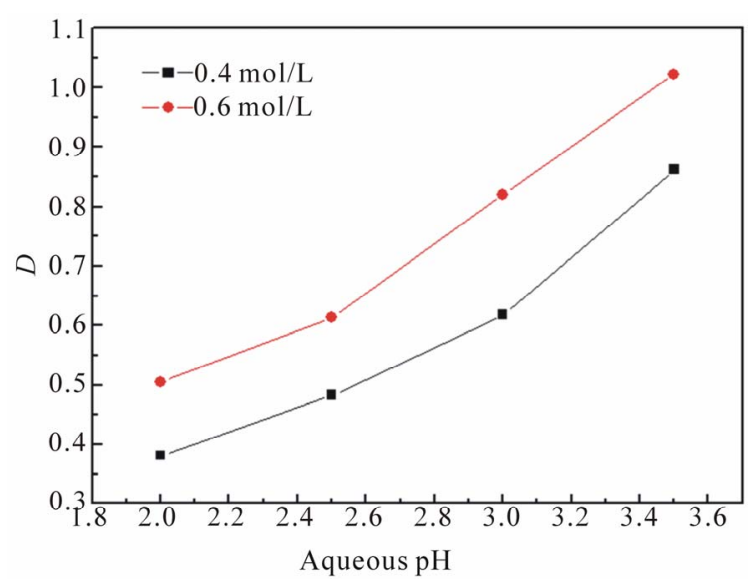

Figure 1. The effect of aqueous $\mathrm{pH}$ on the extraction of La(III).

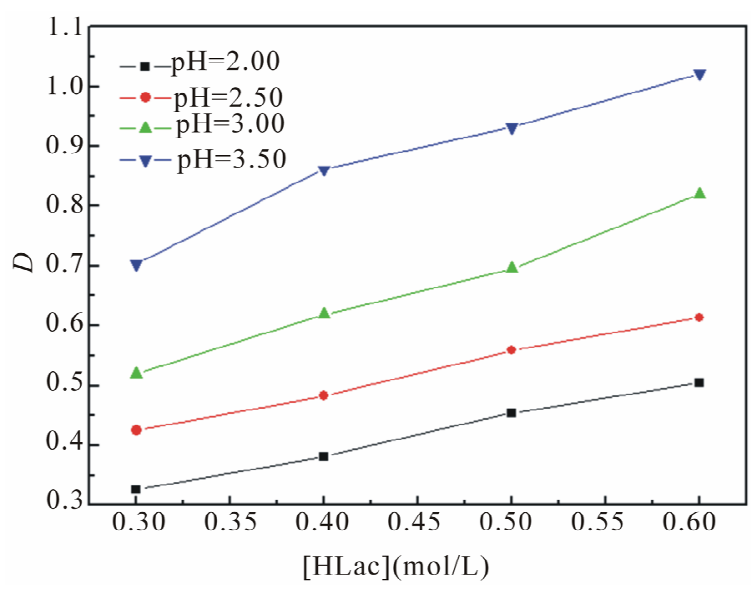

Figure 2. The effect of lactic acid concentration on the extraction of $\mathrm{La}(\mathrm{III})$. 
the key links in industrial processes. To our knowledge, extraction abilities of acidic organophosphorous extractants are commonly effected by the hydrogen ion from the hydroxyl group in P204 [19]. As a rule, the extraction of the trivalent rare-earth ions with P204 is an ion-exchange mechanism (Equation (2)). The rare earths extraction efficiency can be decreased due to the increase of the acidity in the raffinate, which is caused by the hydrogen ions exchanged with rare earth ions. To overcome the disadvantages, the acidic extractants saponified with aqueous ammonia have been widely applied for the extraction (Equation (3)), but saponification will result in serious pollution, emulsification and the third phase formation during extraction. Therefore, the careful control of the acidity in the raffinate is a critical component to the successful operation of the extraction process. The application of lactic acid is an effective strategy for eliminating this phenomenon, as shown in Equation (4), where " $\mathrm{x}$ " is the number of the ligand, and equals to 1,2 or 3, and Lac is the lactate ion. The rare-earth ions in the aqueous phase can form a variety of complexes in the presence of lactic acid. However, a particular complex is prominent in the feed solution under the experimental conditions. After extraction, some hydrogen ions in the raffinate can combine with the lactate, which reduces the acidity in the aqueous phase and slows down the effect of higher acidity in the raffinate on the distribution ratios. On the other hand, no ammonium ion is released in the extraction process, indicating that it is a better environment-friendly process than the saponification extraction method.

$$
\begin{gathered}
\mathrm{RE}^{3+}+3 \mathrm{H}_{2} \mathrm{~A}_{2}=\mathrm{RE}\left(\mathrm{HA}_{2}\right)_{3}+3 \mathrm{H}^{+} \\
\mathrm{H}_{2} \mathrm{~A}_{2}+2 \mathrm{NH}_{3} \cdot \mathrm{H}_{2} \mathrm{O}=2 \mathrm{NH}_{4}^{+} \mathrm{A}^{-}+2 \mathrm{H}_{2} \mathrm{O} \\
\mathrm{RE}(\mathrm{Lac})_{\mathrm{x}(a)}^{(3-\mathrm{x})+}+3 \mathrm{H}_{2} \mathrm{~A}_{2(o)} \\
=\mathrm{REA}_{3} \cdot 3 \mathrm{HA}_{(o)}+(3-\mathrm{x}) \mathrm{H}_{(a)}^{+}+\mathrm{xHLac}_{(a)}
\end{gathered}
$$

\subsection{Separation Performance}

It is of considerable interest to quantitatively compare the separation ability. Under equilibrium conditions, the separation factors of the adjacent rare earth elements, $\beta$, can be defined as:

$$
\beta=\frac{D_{2}}{D_{1}}
$$

where the $D_{1}$ and $D_{2}$ refer to the distribution ratios of metal ion 1 and metal ion 2, respectively. Generally, the value of $D_{2}$ is larger than that of $D_{1}$.

As can be seen from Table 1, the separation factors for $\mathrm{Ce} / \mathrm{La}, \mathrm{Pr} / \mathrm{La}$ and $\mathrm{Nd} / \mathrm{La}$ increase with the aqueous $\mathrm{pH}$ value increasing at HLac concentration of $0.6 \mathrm{~mol} / \mathrm{L}$. For example, at $\mathrm{pH} 3.5$ and HLac concentration of $0.6 \mathrm{~mol} / \mathrm{L}$ in the range studied, the separation factors for $\mathrm{Ce} / \mathrm{La}$, $\mathrm{Pr} / \mathrm{La}$ and $\mathrm{Nd} / \mathrm{La}$ become values of 3.42, 6.98 and 11.16. From the separation factors, we can come to the conclusion that this system should be a more effective method to separate $\mathrm{La}^{3+}$ from the other rare earths.

\subsection{Recycling Experiments of the Complexing Agent HLac}

As for the above experimental results, this system could be considered an efficient potential method for separating REs. However, there is a standard about the waste-water containing high organic loadings in the rare earths industry, otherwise, it will affect the chemical oxygen demand (COD). So the treatment of HLac from the extraction system becomes an important issue. In this study, we determine the optimum conditions by orthogonal test firstly when the lactic acid concentration is $0.6 \mathrm{~mol} / \mathrm{L}$. Using a countercurrent extraction process at a phase ratio $V_{\mathrm{o}}: V_{w}=1: 1, \mathrm{t}=20^{\circ} \mathrm{C}, \mathrm{pH}=0.6$, and $75 \mathrm{vol} \% \mathrm{TBP}$ in kerosene, the HLac recovery reaches more than $99 \%$ for 10 extraction stages as shown in Table 2.

In order to evaluate whether the lactic acid concentration achieves the emission standards of pollutants from rare earths industry or not, we calculate the COD in the raffinate after the 11 extraction stages. As can be seen from the Table 3, the COD value after the 11 extraction stages can be up to $57.7 \mathrm{mg} / \mathrm{L}$, which meets the emission standards of pollutants from rare earths industry (COD $\leq$ $80 \mathrm{mg} / \mathrm{L}$ ), where theory of chemical oxygen demand of HLac is $1.07 \mathrm{~g} / \mathrm{g}$ [20]. The results indicate that the HLac can be effectively recycled.

Table 1. Separation factors $\left(D_{\mathrm{i}} / D_{\mathrm{La}}\right)$ under the experimental conditions.

\begin{tabular}{ccccc}
\hline $\mathrm{pH}$ & 2 & 2.5 & 3 & 3.5 \\
\hline$\beta_{\text {Ce/La }}$ & 2.42 & 2.8 & 3 & 3.42 \\
$\beta_{\text {Pr/La }}$ & 3.92 & 4.82 & 5.58 & 6.98 \\
$\beta_{\text {Nd/La }}$ & 5.1 & 6.5 & 8.04 & 11.16 \\
\hline
\end{tabular}

Table 2. Extraction efficiencies (E\%) of each row.

\begin{tabular}{ccccccc}
\hline Parameter & Stages & 1 & 2 & 3 & 4 & 5 \\
\hline Row 1 (E\%) & HLac & 0 & 0.06 & 0.21 & 1.01 & 1.91 \\
Row 2 (E\%) & HLac & 0.05 & 0.13 & 0.65 & 1.57 & 3.8 \\
Row 3 (E\%) & HLac & 0.67 & 1.46 & 1.98 & 7.98 & 9.85 \\
Parameter & Stages & 6 & 7 & 8 & 9 & 10 \\
Row 1 (E\%) & HLac & 22.22 & 59.65 & 84.81 & 97.31 & 99.19 \\
Row 2 (E\%) & HLac & 24.2 & 49.09 & 77.85 & 91.93 & 99.18 \\
Row 3 (E\%) & HLac & 15.23 & 41.78 & 67.53 & 88.53 & 99.19 \\
\hline
\end{tabular}


Table 3. The experimental results of multistage countercurrent extraction.

\begin{tabular}{ccccc}
\hline \multicolumn{2}{c}{ Parameter } & \multicolumn{3}{c}{10 stages countercurrent extraction } \\
Mass concentration & Feed $(\mathrm{g} / \mathrm{L})$ & $\mathrm{E} \%$ & Raffinate & COD (mg/L) \\
HLac & 54.048 & 99.2 & 0.4 & 428 \\
Parameter & 11 stages countercurrent extraction \\
& E\% & Raffinate & COD (mg/L) \\
& 99.9 & 0.054 & 57.7 \\
\hline
\end{tabular}

\section{Conclusions}

The following conclusions are drawn:

1) The distribution ratios of the extraction of $\mathrm{La}$ (III) by P204 increase with the increase of the $\mathrm{pH}$ value in the feed solution and lactic acid concentration. The maximum separation factors of $\mathrm{Ce} / \mathrm{La}, \operatorname{Pr} / \mathrm{La}$ and $\mathrm{Nd} / \mathrm{La}$ become values of 3.42, 6.98 and 11.16 at $\mathrm{pH} 3.5$ and HLac concentration of $0.6 \mathrm{~mol} / \mathrm{L}$.

2) The recycling experiments show that the complexing agent lactic acid could be efficiently recycled, and the COD in the raffinate meets the emission standards of pollutants from rare earths industry.

\section{Acknowledgements}

Financial aid from the following programs is gratefully acknowledged: the National Natural Science Foundation of China (50974042, 51104040 and 51274060), the National Program on Key Basic Research Project of China (973 Program) (2012CBA01205), the National Key Technology Research and Development Program of the Ministry of Science and Technology of China (2012BAE01B00) and the Scientific Research special Foundation of Doctor subject of Chinese Universities (20100042110008).

\section{REFERENCES}

[1] D. H. Cheng, X. W. Chen, Y. Shu and J. H. Wang, "Selective Extraction/Isolation of Hemoglobin with Ionic Liquid 1-Butyl-3-trimethylsilylimidazolium Hexafluorophosphate (BtmsimPF6)," Talanta, Vol. 75, No. 5, 2008, pp. 1270-1278. doi:10.1016/j.talanta.2008.01.044

[2] X. W. Huang, H. W. Li, X. X. Xue and G. C. Zhang, "Development Status and Research Progress in Rare Earth Hydrometallurgy in China," Journal of the Chinese Rare Earth Society, Vol. 24, No. 2, 2006, pp. 129-133.

[3] Z. G. Zhu and J. G. Cheng, "The Research on Waste Water's Processing Method by Rare Earth Hydrometallurgy," China's Manganese Industy, Vol. 28, No. 3, 2010, pp. 34-36.

[4] Z. F. Zhang, H. F. Li, F. Q. Guo, S. L. Meng and D. Q. Li, "Synergistic Extraction and Recovery of Cerium(IV) and Fluorin from Sulfuric Solutions with Cyanex 923 and Di-2-ethylhexyl Phosphoric Acid," Separation and Puri- fication Technology, Vol. 63, No. 2, 2008, pp. 348-352. doi:10.1016/j.seppur.2008.05.023

[5] N. Z. Song, S. S. Tong, W. Liu, Q. Jia, W. H. Zhou and W. P. Liao, "Extraction and Separation of Rare Earths from Chloride Medium with Mixtures of 2-Ethylhexylphosphonic Acid Mono-(2-ethylhexyl) Ester and SecNonylphenoxy Acetic Acid," Journal of Chemical Technology and Biotechnology, Vol. 63, No. 12, 2009, pp. 1798-1802. doi:10.1002/jctb.2248

[6] X. H. Luo, X. W. Huang, Z. W. Zhu, Z. Q. Long and Y. J. Liu, "Synergistic Extraction of Cerium From Sulfuric Acid Medium Using Mixture of 2-Ethylhexyl Phosphonic Acid Mono 2-Ethylhexyl Ester and Di-(2-ethyl hexyl) Phosphoric Acid as Extractant," Journal Rare Earths, Vol. 27, No. 1, 2009, pp. 119-122. doi:10.1016/S1002-0721(08)60204-5

[7] X. Q. Sun, Y. Ji, F. C. Hu, B. He, J. Chen and D. Q. Li, "The Inner Synergistic Effect of Bifunctional Ionic Liquid Extractant for Solvent Extraction," Talanta, Vol. 81, No. 4-5, 2010, pp. 1877-1883.

doi:10.1016/j.talanta.2010.03.041

[8] V. M. Egorov, D. I. Djigailo, D. S. Momotenko, D. V. Chernyshov, I. I. Torocheshnikova, S. V. Smirnova and I. V. Pletnev, "Task-Specific Ionic Liquid Trioctylmethylammonium Salicylate as Extraction Solvent for Transition Metal Ions," Talanta, Vol. 80, No. 3, 2010, pp. 1177 1182. doi:10.1016/j.talanta.2009.09.003

[9] W. Wang, H. L.Yang, H. M. Cui, D. L. Zhang, Y. Liu and J. Chen, "Application of Bifunctional Ionic Liquid Extractants [A336][CA-12] and [A336][CA-100] to the Lanthanum Extraction and Separation from Rare Earths in the Chloride Medium," Industrial and Engineering Chemistry Research, Vol. 50, No. 12, 2011, pp. 75347541. doi:10.1021/ie2001633

[10] X. B. Sun, Y. G. Wang and D. Q. Li, "Selective Separation of Yttrium by CA-100 in the Presence of a Complexing Agent," Rare Earths 2004 Conference, Nara, 7-12 November 2004, pp. 999-1002.

[11] S. Sujatha, M. L. P. Reddy, T. R. Ramamohan and A. D. Damodaran, "Effect of Water Soluble Complexing Agent on the Extraction of $\mathrm{Ce}(\mathrm{III})$ and $\mathrm{Nd}(\mathrm{III})$ by 2-Ethylhexylphosphonic Acid Mono-2-ethylhexyl Ester," Journal of Radioanalytical and Nuclear Chemistry, Vol. 174, No. 2, 1993, pp. 271-278. doi:10.1007/BF02037914

[12] S. Nishihama, T. Hirai and I. Komasawa, "Advanced Liquid-Liquid Extraction Systems for the Separation of Rare Earth Ions by Combination of Conversion of the Metal Species with Chemical Reaction," Journal of Solid State Chemistry, Vol. 171, No. 1-2, 2003, pp. 101-108. doi:10.1016/S0022-4596(02)00198-6

[13] S. Nishihama, T. Hirai and I. Komasawa, "Selective Extraction of $\mathrm{Y}$ from a Ho/Y/Er Mixture by Liquid-Liquid Extraction in the Presence of a Water-Soluble Complexing Agent," Industrial and Engineering Chemistry Research, Vol. 39, No. 10, 2000, pp. 3907-3911. doi:10.1021/ie000030a

[14] Y. G. Wang, Y. Xiong, S. L. Meng and D. Q. Li, "Separation of Yttrium from Heavy Lanthanide by CA-100 
Using the Complexing Agent," Talanta, Vol. 63, No. 2, 2004, pp. 239-243. doi:10.1016/j.talanta.2003.09.034

[15] S. Nishihama, T. Hirai and I. Komasawa, "Review of Advanced Liquid Liquid Extraction Systems for the Separation of Metal Ions by a Combination of Conversion of the Metal Species with Chemical Reaction," Industrial and Engineering Chemistry Research, Vol. 40, No. 14, 2001, pp. 3085-3091. doi:10.1021/ie010022+

[16] X. Q. Sun, B. Peng, J. Chen, D. Q. Li and F. Luo, “An Effective Method for Enhancing Metal-Ions' Selectivity of Ionic Liquid-Based Extraction System: Adding WaterSoluble Complexing Agent," Talanta, Vol. 74, No. 4, 2008, pp. 1071-1074. doi:10.1016/j.talanta.2007.07.031

[17] H. T. Chang, W. Y. Wu, G. F. Tu, Y. H. Zhao, D. Li and X. Y. Sang, "Extraction of Light Rare Earth in the System of P204-HCl-H $\mathrm{H}_{3}$ cit," Chinese Rare Earths, Vol. 28, No. 3, 2008, pp. 18-21.
[18] S. H. Yin, W. Y. Wu, X. Bian and F. Y. Zhang, "Effect of Complexing Agent Lactic Acid on the Extraction and Separation of $\operatorname{Pr}(\mathrm{III}) / \mathrm{Ce}(\mathrm{III})$ with Di-(2-ethylhexyl) Phosphoric Acid," Hydrometallurgy, Vol. 131-132, 2013, pp. 133-137. doi:10.1016/j.hydromet.2012.11.005

[19] N. V. Thakur, D. V. Jayawant, N. S. Iyer and K. S. Koppiker, "Separation of Neodymium from Lighter Rare Earths Using Alkyl Phosphonic Acid, PC88A," Hydrometallurgy, Vol. 34, No. 1, 1993, pp. 99-108. doi:10.1016/0304-386X(93)90084-Q

[20] X. K. Wu and Q. P. Jin, "Treatment Technology of Organic Wastewater," East China Institute of Chemical Press, Shanghai, 1989. 